\title{
Study on the Role of Supersonic Nozzle in Fiber Laser Cutting of Stainless Steel
}

\author{
Yijun Zhou, Jilan Kong, Jin Zhang \\ Yang Zhou Polytechnic College, Jiangsu, China \\ Email: carlzhouyijun@163.com
}

How to cite this paper: Zhou, Y.J., Kong, J.L. and Zhang, J. (2017) Study on the Role of Supersonic Nozzle in Fiber Laser Cutting of Stainless Steel. Materials Sciences and Applications, 8, 85-93.

http://dx.doi.org/10.4236/msa.2017.81006

Received: November 21, 2016

Accepted: January 8, 2017

Published: January 11, 2017

Copyright (๑) 2017 by authors and Scientific Research Publishing Inc. This work is licensed under the Creative Commons Attribution International License (CC BY 4.0).

http://creativecommons.org/licenses/by/4.0/

\begin{abstract}
Striation-free laser cutting, especially for thick section steel, is hard to obtain due to several factors. The inside shape of the gas nozzle is considered to be one of the most vital factors in striation-free fiber laser cutting. $0.8 \mathrm{~mm}$ normal nozzle and a supersonic nozzle are used to cut $0.8 \mathrm{~mm}$ AISI316L stainless steel $\left(0_{22} \mathrm{Cr}_{17} \mathrm{Ni}_{12} \mathrm{Mo}_{2}\right)$ separately. The orthogonal experiment takes nozzle standoff distance, cutting speed, Laser power and gas pressure as its impacting factors. The same orthogonal table is adopted in different condition, using normal nozzle and using supersonic nozzle. In the mean time, Ar gas is used as assisted cutting gas in the experiment. The data from this experiment show that supersonic nozzle seems to be a strong helper for fiber laser cutting. Feed rate's effect seems stable and inconspicuous under the condition of using supersonic nozzle.
\end{abstract}

\section{Keywords}

Fiber Laser Cutting, Stainless Steel, Striation, Supersonic Nozzle

\section{Introduction}

Striation-free laser cutting, especially for thick section steel, is hard to obtain due to several factors. There are quite a few scholars who were engaged in this issue recently. People believed that the inside shape of the gas nozzle is considered to be one of the most vital factors during striation-free fiber laser cutting [1]-[25].

Nozzle's function in laser cutting is considered as assisting cutting process. Normal nozzle seems to be easy causing unstable gas flow which is one of the probabilities to generate striation. So many scholars pay more attention to design of supersonic gas nozzle. Figure 1 shows the short cutting structure of supersonic nozzle. This structure was studied by Guo Shaogang et al. (2007) [26], which can obtain the uniform flow and the optimum dynamic characteristic and is easier to be made than before. 


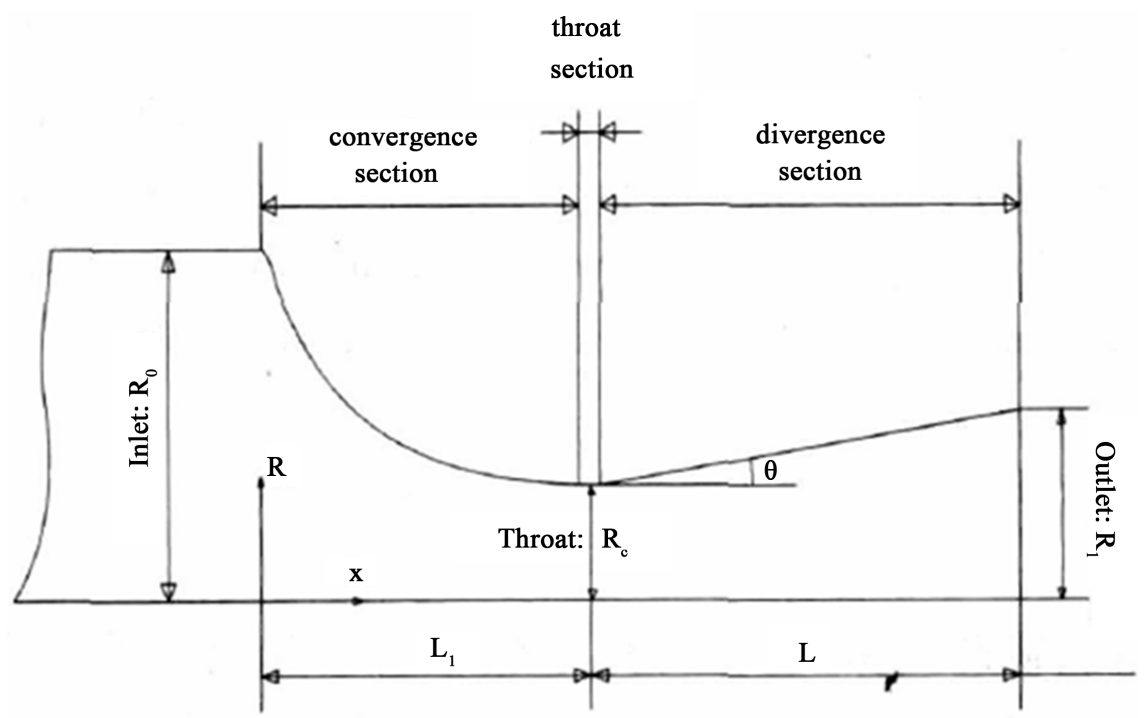

Figure 1. The short cutting structure of supersonic nozzle [26].

However, people still doubt about which kind impact of this kind of supersonic nozzle. So what we interested here is try to test the purpose of the inside shape of the gas nozzle which is considered to be one of the most vital factors in striation-free fiber laser cutting. $0.8 \mathrm{~mm}$ normal nozzle and a supersonic nozzle, which was modified of $0.8 \mathrm{~mm}$ normal nozzle, are used in this experiment. The orthogonal experiment takes nozzle standoff distance, cutting speed, Laser power and gas pressure as its impacting factors. The same orthogonal table is adopted in each condition.

\section{Experimental Procedures}

\subsection{The Laser System and Cutting Material}

The work pieces used in the experiments were as-received $0.8 \mathrm{~mm}$ thick AISI316L stainless sheets $\left(0_{22} \mathrm{Cr}_{17} \mathrm{Ni}_{12} \mathrm{Mo}_{2}\right)$. Laser cutting experiments were conducted using a $1 \mathrm{~kW}$ continuous wave $(\mathrm{cw})$ IPG YLR-1000-SM ytterbium single-mode fiber laser with $1.07 \mu \mathrm{m}$ wavelength, a TEM00 beam intensity distribution, and a $14 \mu \mathrm{m}$ delivery fiber core diameter. The beam has an M2 of 1.1. After the delivery optical fiber, the laser beam was collimated to a $3 \mathrm{~mm}$ diameter and focused using a lens of 7.5 inch focal length. The laser beam spot size at focus was measured to be $62 \mu \mathrm{m}$. During laser cutting experiments the laser power was varied between 800 and $1000 \mathrm{~W}$ and the cutting speed between 10 and $30 \mathrm{~mm} / \mathrm{s}$. Focal position was varied between $5 \mathrm{~mm}$ below the work piece surface, and $13 \mathrm{~mm}$ above the surface.

A Practice laser cutting head with a coaxial conical nozzle and a $0.8 \mathrm{~mm}$ exit hole diameter was used. The nozzle standoff from the work piece was varied between 1 and $2 \mathrm{~mm}$. The work piece was placed on a CNC x-y table below the stationary laser beam as shown in Figure 2. Ar gas was used with the regulator gas pressure set between 1.0 and 2.0 bar. The laser cut samples were analyzed by using an optical microscopy. 


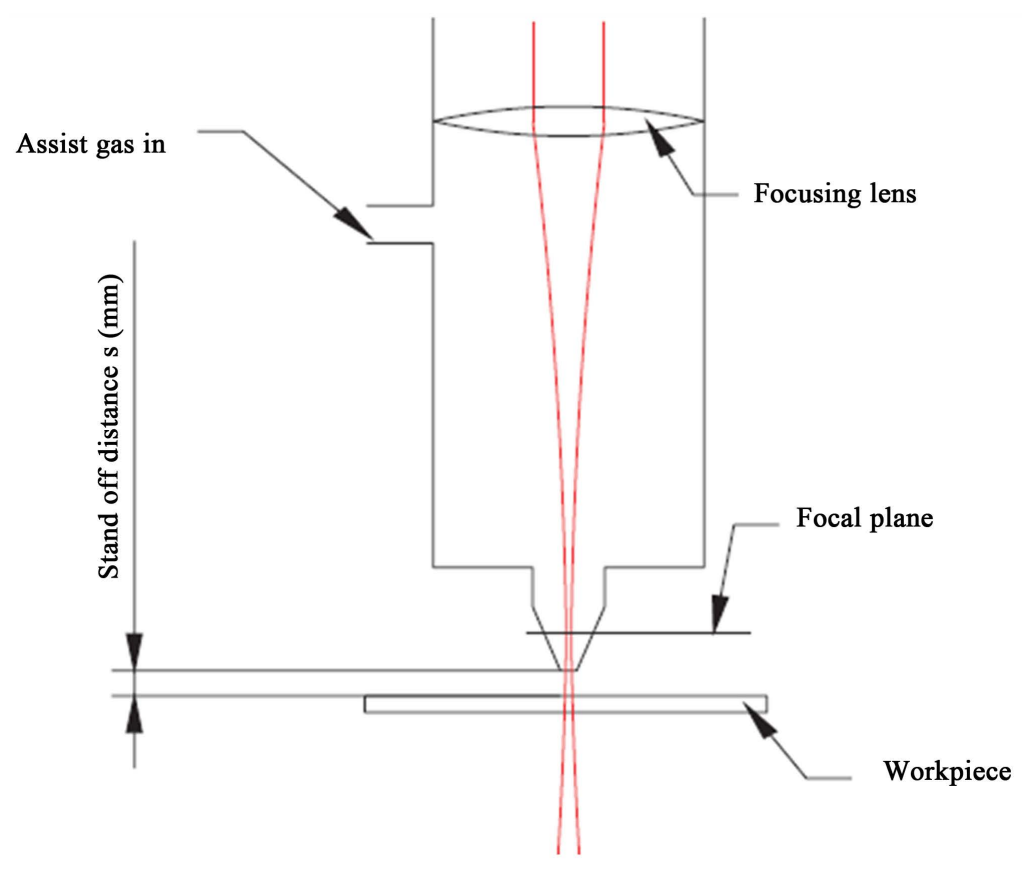

Figure 2. Experimental set up for the laser cutting trials.

\subsection{Inside Shape Supersonic Nozzle}

There is a coaxial conical nozzle and a $0.8 \mathrm{~mm}$ exit hole diameter inside normal cutting head. Normal nozzle does not have a throat, while supersonic nozzle should have a throat near the end of gas outlet. So the supersonic nozzle was modified from normal cutting nozzle. There is a chamfer at the end of its exit hole which could be shown in Figure 3. The diameter $d c$ is $1.76 \mathrm{~mm}$, and diameter $d o$ is $2.26 \mathrm{~mm}$ and $L O$ is $2.0 \mathrm{~mm}$.

\subsection{The Optimization Algorithm}

There are four controlling factors in this optimization algorithm experiment. Table 1 shows their levels in details used in experimentation.

Table 2 shows the standard $\mathrm{L} 4^{3}$ test schedule which was used in laser cutting with normal nozzle as well as supersonic nozzle.

\section{Results}

\subsection{Synthesis Analysis}

In this optimization algorithm, roughness, which could be measured by using a LSM 7003 D Laser Scanning Microscope on the cutting section of each sample, is considered as the index of evaluation of the analysis by synthesis. According to specific circumstance, the calculation formula shows below.

$$
K_{i}=\left[1-\left(T_{i}-T_{\min }\right) /\left(T_{\max }-T_{\min }\right)\right] \times 100
$$

In Formula (1), $i$ stands for test piece number; $T_{i}$ stands for roughness; $T_{\max }$ stands for the maximum roughness; $T_{\min }$ stands for the minimize roughness; $K_{i}$ stands for synthesize analysis score of each sample. 


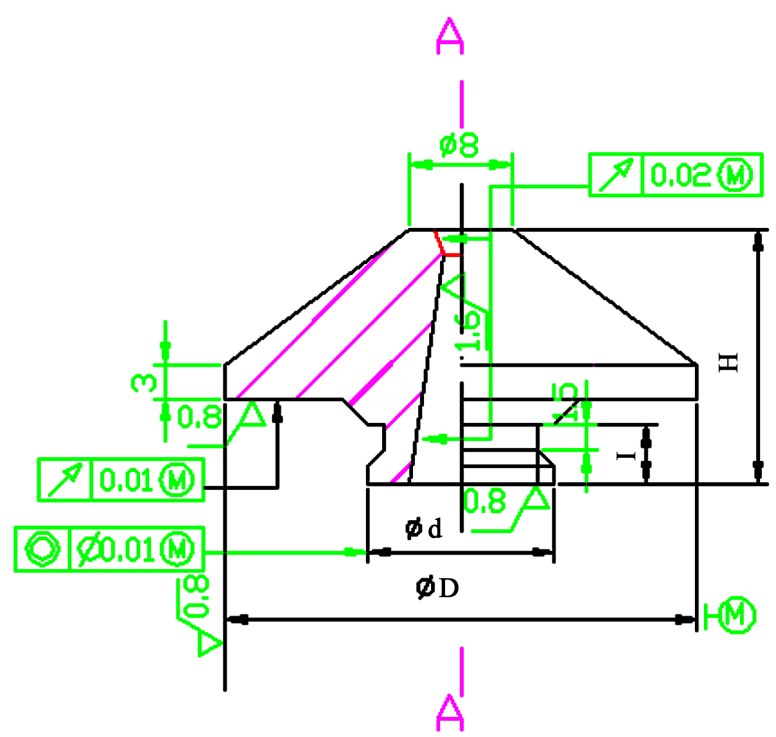

$A-A$

Figure 3. Modified supersonic nozzle

Table 1. Control factors and their levels used in experimentation.

\begin{tabular}{cccccc}
\hline Level & Factor & $\begin{array}{c}\text { Standoff distance } \\
\mathrm{mm}\end{array}$ & $\begin{array}{c}\text { Gas pressure } \\
\mathrm{kgf} / \mathrm{cm}^{2}\end{array}$ & $\begin{array}{c}\text { Power } \\
\mathrm{W}\end{array}$ & $\begin{array}{c}\text { Feed rate } \\
\mathrm{mm} / \mathrm{s}\end{array}$ \\
\cline { 2 - 5 } & Symbol & $T$ & $p$ & $m$ & $\mathrm{~V}$ \\
\hline 1 & $T_{1}(1)$ & $p_{1}(1.0)$ & $m_{1}(600)$ & $V_{1}(10)$ \\
2 & $T_{2}(1.5)$ & $p_{2}(1.5)$ & $m_{2}(800)$ & $V_{2}(20)$ \\
3 & $T_{3}(2)$ & $p_{3}(2.0)$ & $m_{3}(1000)$ & $V_{3}(30)$ \\
\hline
\end{tabular}

Table 2. The test schedule using $0.8 \mathrm{~mm}$ Nozzle and $A r$.

\begin{tabular}{|c|c|c|c|c|c|c|}
\hline \multirow{3}{*}{ Test number } & Column number & 1 & 2 & 3 & 4 & \multirow{3}{*}{ Score } \\
\hline & Factor & $\begin{array}{c}\text { Standoff } \\
\text { distance } \mathrm{mm}\end{array}$ & $\begin{array}{c}\text { Gas pressure } \\
\mathrm{kgf} / \mathrm{cm}^{2}\end{array}$ & $\begin{array}{c}\text { Power } \\
\text { W }\end{array}$ & $\begin{array}{l}\text { Feed } \\
\mathrm{mm} / \mathrm{s}\end{array}$ & \\
\hline & Symbol & $T$ & $p$ & $m$ & v & \\
\hline 1 & & $1\left(T_{1}\right)$ & $1\left(p_{1}\right)$ & $1\left(m_{1}\right)$ & $1\left(v_{1}\right)$ & 71 \\
\hline 2 & & $1\left(T_{1}\right)$ & $2\left(p_{2}\right)$ & $2\left(m_{2}\right)$ & $2\left(V_{2}\right)$ & 57 \\
\hline 3 & & $1\left(T_{1}\right)$ & $3\left(p_{3}\right)$ & $3\left(m_{3}\right)$ & $3\left(v_{3}\right)$ & 74 \\
\hline 4 & & $2\left(T_{2}\right)$ & $1\left(p_{1}\right)$ & $2\left(m_{2}\right)$ & $3\left(v_{3}\right)$ & 90 \\
\hline 5 & & $2\left(T_{2}\right)$ & $2\left(p_{2}\right)$ & $3\left(m_{3}\right)$ & $1\left(V_{1}\right)$ & 68 \\
\hline 6 & & $2\left(T_{2}\right)$ & $3\left(p_{3}\right)$ & $1\left(m_{1}\right)$ & $2\left(V_{2}\right)$ & 0 \\
\hline 7 & & $3\left(T_{3}\right)$ & $1\left(p_{1}\right)$ & $3\left(m_{3}\right)$ & $2\left(V_{2}\right)$ & 47 \\
\hline 8 & & $3\left(T_{3}\right)$ & $2\left(p_{2}\right)$ & $1\left(m_{1}\right)$ & $3\left(v_{3}\right)$ & 96 \\
\hline 9 & & $3\left(T_{3}\right)$ & $3\left(p_{3}\right)$ & $2\left(m_{2}\right)$ & $1\left(v_{1}\right)$ & 65 \\
\hline
\end{tabular}

\subsection{Range Analysis}

Range analysis can be used to calculate the range $R$, using mathematical statistics to work out, in each collar of orthogonal table; and the primary and secondary 
relationship of every factor could be based on its value. According to the value of the range, people can look for reasonable combining parameters of fiber cutting machine. The calculation formula shows below.

$$
R_{j k}=K_{i(\max )}-K_{i(\min )}
$$

In Formula (2), subscript $j$ stands for level of the optimization algorithm; $k$ stands for impacting factor of the optimization algorithm. $\Delta R$ equals to the Maximum among I, II, III in $K$ collar minus the Minimum among I, II, III in $K$ collar inside Table 3.

\subsection{Analyzing Relationship between Factors and Indexes under the Condition of Using $0.8 \mathrm{~mm}$ Nozzle}

(1) Analyzing datum inside Table 2, the 8 th test sample seems the best one, to which its level combing is $A_{3} B_{2} C_{1} D_{3}$; the 6th test sample seems the worst one, to which its level combing is $A_{2} B_{3} C_{1} D_{2}$.

(2) The primary and secondary relationship of 4 factors in Table 3 and Figure 4 shows their rank order: $D \rightarrow B \rightarrow A \rightarrow C$. Factor $D$ could be found that its impact dominated among the four factors. $A, B$ and $C$ factors' effect seems that there was so little difference between them.

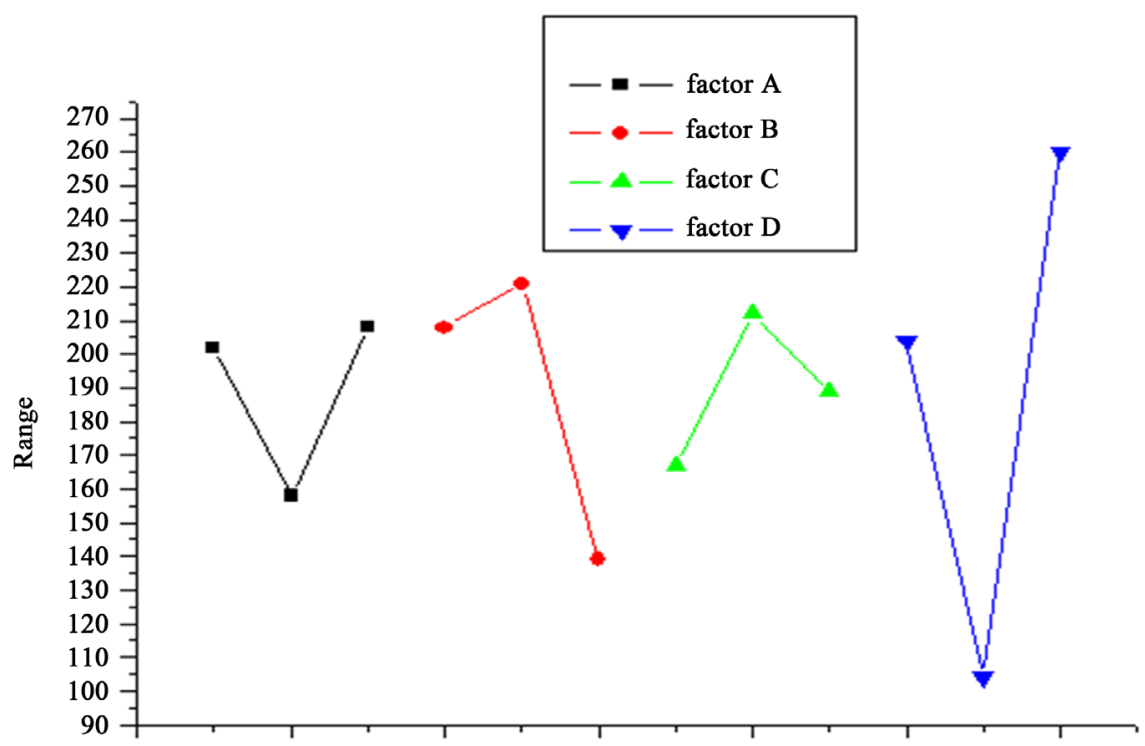
$\mathrm{A}_{1}$
$\mathrm{A}_{2} \quad \mathrm{~A}_{3} \quad \mathrm{~B}$
$\mathrm{B}_{2} \quad \mathrm{~B}_{3} \quad \mathrm{C}_{1} \quad \mathrm{C}_{2}$

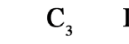
$\mathrm{D}_{2} \quad \mathrm{D}_{3}$

Figure 4. Relationships between striation and four factors.

Table 3. Range of using normal nozzle.

\begin{tabular}{cccccc}
\hline Range & Standoff distance $\mathrm{mm}$ & Gas pressure $\mathrm{kgf} / \mathrm{cm}^{2}$ & Power W & Feed $\mathrm{mm} / \mathrm{s}$ & Sum \\
\hline I & 202 & 208 & 167 & 204 & \\
II & 158 & 221 & 212 & 104 & \\
III & 208 & 139 & 189 & 260 & 568 \\
$\Delta \mathrm{R}$ & 50 & 69 & 45 & 156 & \\
\hline
\end{tabular}




\subsection{Analyzing Relationship between Factors and Indexes under the Condition of Using $0.8 \mathrm{~mm}$ Supersonic Nozzle}

(1) Analyzing datum inside Table 4, the 2th test sample seems the best one, to which its level combing is $A_{1} B_{2} C_{2} D_{2}$; the 7th test sample seems the worst one, to which its level combing is $A_{3} B_{1} C_{3} D_{2}$. But, its score can compare with average score under the condition of using $0.8 \mathrm{~mm}$ normal nozzle.

(2) The primary and secondary relationship of 4 factors in Table 5 and Figure 5 shows their rank order: $A \rightarrow B \rightarrow C \rightarrow D$. Factor $A$ could be found that its impact dominated among the four factors. $B, C$ factors' effect seems that there was so little difference between them. Factor $D$ s effect seems stable and inconspicuous under the condition of using supersonic nozzle.

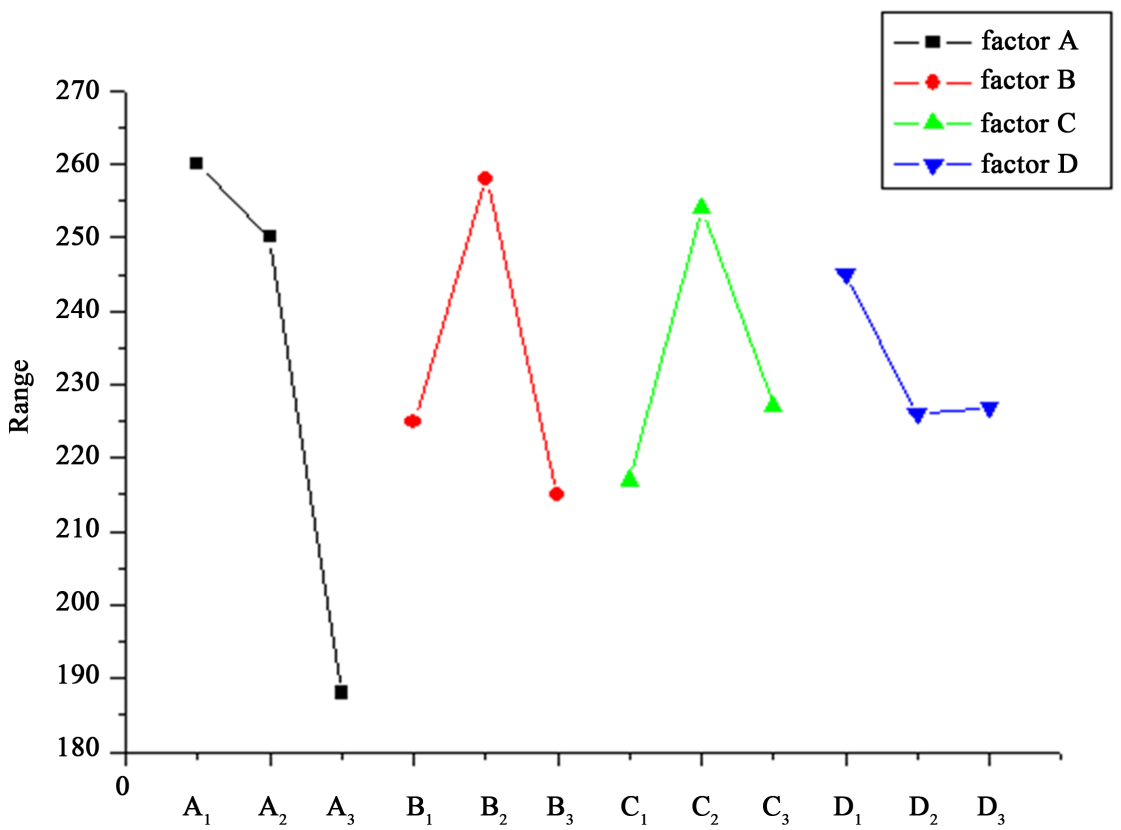

Figure 5. Relationships between striation and four factors.

Table 4. The test schedule using $0.8 \mathrm{~mm}$ Supersonic Nozzle and Ar.

\begin{tabular}{ccccccc}
\hline \multirow{2}{*}{$\begin{array}{c}\text { Test } \\
\text { number }\end{array}$} & Columnnumber & 1 & 2 & 3 & \multicolumn{2}{c}{4} \\
\cline { 2 - 5 } & Factor & $\begin{array}{c}\text { Standoff } \\
\text { distance } \mathrm{mm}\end{array}$ & $\begin{array}{c}\text { Gas pressure } \\
\mathrm{kgf} / \mathrm{cm}^{2}\end{array}$ & $\begin{array}{c}\text { Power } \\
\mathrm{W}\end{array}$ & $\begin{array}{c}\text { Feed } \\
\mathrm{mm} / \mathrm{s}\end{array}$ & \\
\cline { 2 - 5 } & Symbol & $T$ & $\mathrm{p}$ & $\mathrm{m}$ & $\mathrm{v}$ & \\
\cline { 2 - 5 } 1 & $1\left(T_{1}\right)$ & $1\left(p_{1}\right)$ & $1\left(m_{1}\right)$ & $1\left(v_{1}\right)$ & 83 \\
2 & $1\left(T_{1}\right)$ & $2\left(p_{2}\right)$ & $2\left(m_{2}\right)$ & $2\left(v_{2}\right)$ & 100 \\
3 & $1\left(T_{1}\right)$ & $3\left(p_{3}\right)$ & $3\left(m_{3}\right)$ & $3\left(v_{3}\right)$ & 77 \\
4 & $2\left(T_{2}\right)$ & $1\left(p_{1}\right)$ & $2\left(m_{2}\right)$ & $3\left(v_{3}\right)$ & 86 \\
5 & $2\left(T_{2}\right)$ & $2\left(p_{2}\right)$ & $3\left(m_{3}\right)$ & $1\left(v_{1}\right)$ & 94 \\
6 & $2\left(T_{2}\right)$ & $3\left(p_{3}\right)$ & $1\left(m_{1}\right)$ & $2\left(v_{2}\right)$ & 70 \\
7 & $3\left(T_{3}\right)$ & $1\left(p_{1}\right)$ & $3\left(m_{3}\right)$ & $2\left(v_{2}\right)$ & 56 \\
8 & $3\left(T_{3}\right)$ & $2\left(p_{2}\right)$ & $1\left(m_{1}\right)$ & $3\left(v_{3}\right)$ & 64 \\
9 & $3\left(T_{3}\right)$ & $3\left(p_{3}\right)$ & $2\left(m_{2}\right)$ & $1\left(v_{1}\right)$ & 68 \\
\hline
\end{tabular}


Table 5. Range of using supersonic nozzle.

\begin{tabular}{cccccc}
\hline Range & Standoff distance $\mathrm{mm}$ & Gas pressure $\mathrm{kgf} / \mathrm{cm}^{2}$ & Power W & Feed $\mathrm{mm} / \mathrm{s}$ & Sum \\
\hline I & 260 & 225 & 217 & 245 & \\
II & 250 & 258 & 254 & 226 & \\
III & 188 & 215 & 227 & 227 & 698 \\
$\Delta \mathrm{R}$ & 72 & 43 & 37 & 19 & \\
\hline
\end{tabular}

\section{Discussion}

There are some differences between normal nozzle laser cutting and supersonic nozzle laser cutting. The primary and secondary relationship between 4 factors of two different conditions is absolutely different. Supersonic nozzle may get a stabilized gas flow, and the stable gas flow can even obtain at a relatively higher feed rate. This is the reason why the total score of test samples inside Table 4 is higher than that inside Table 2.

The range of $D$ factor (feed rate) becomes small when supersonic nozzle is used. This is another clue that shows supersonic nozzle could obtain a relative stable gas flow.

However, there is a same result between normal nozzle laser cutting and supersonic nozzle laser cutting. The best properly combined parameters is $A_{1} B_{2} C_{2} D_{1}$. The tendency of factor $A, B$ and $C$ in different conditions seems similar.

There are more than 4 factors which can affect the cutting quality, and may result in striation on the section of work pieces. The value of different level of each factor inside the optimization algorithm is setted according to real condition of fiber laser cutting such as thickness of stainless steel and the type of fiber cutting machine. The supersonic nozzle using here does not have an arc shape at convergence section showing in Figure 1. These limitations will make the result, which we get before, uncertain.

\section{Conclusions}

Supersonic nozzle seems to have two functions. One is that it could weak the impact of feed rate in fiber laser cutting of stainless steel; the other is that it could improve cutting quality of stainless steel fiber laser cutting. These functions could be useful for application of fiber laser cutting.

Whichever kind of nozzle is used in fiber laser cutting, tendency of factor $A, B$ and $C$ to cutting quality is similar. According to this result, it is accessible to obtain reasonable combine parameters by optimization algorithm. There is a same result between normal nozzle laser cutting and supersonic nozzle laser cutting. The best properly combined parameters seems to be $A_{1} B_{2} C_{2} D_{1}$ here.

Supersonic nozzle may be better than normal nozzle if we plan to eliminate the striation on the section of work pieces in fiber laser cutting.

\section{References}

[1] Li, L., Sobih, M. and Crouse, P.L. (2007) Striation-Free Laser Cutting of Mild Steel 
Sheets. Annals of the CIRP, 56, 193-196. https://doi.org/10.1016/j.cirp.2007.05.047

[2] Jin, Q.S. and Lou, C.H. (2004) Application of Laser Cutting in the Design and Manufacture of Bridge Case. Modern Manufacturing Engineering, 4, 95-96.

[3] Golnabi, H. and Bahar, M. (2009) Investigation of Optimum Condition in Oxygen Gas-Assisted Laser Cutting. Optical \& Laser Technology, 41, 454-600. https://doi.org/10.1016/j.optlastec.2008.08.001

[4] Sobih, M., Lcoruse, P. and Li, L. (2008) Striation-Free Fiber Laser Cutting of Mild Steel Sheets. Applied Physics A, 90, 171-174. https://doi.org/10.1007/s00339-007-4247-7

[5] Rao, B.T. and Nath, A.K. (2002) Melt Flow Characteristics in Gas-Assisted Laser Cutting. Sadhana, 27, 569-575. https://doi.org/10.1007/BF02703295

[6] Byoung-Cheol, K., To-Hoon, K., et al. (2001) Investigation of Striation Formation in Thin Stainless Steel Tube during Pulsed Nd:YAG Laser Cutting Process by $\mathrm{Nu}$ merical Simulation. Metallurgical and Materials Transactions, 32, 2623. https://doi.org/10.1007/s11661-001-0052-7

[7] Yilbas, B.S. (2008) Laser Cutting of Thick Sheet Metals: Effects of Cutting Parameters on Kerf Size Variations. Journal of Materials Processing Technology, 201, 285290. https://doi.org/10.1016/j.jmatprotec.2007.11.265

[8] Tani, G., Tomesani, L. and Campana, G. (2003) Predication of Melt Geometry in Laser Cutting. Applied Surface Science, 208-209, 142-147.

https://doi.org/10.1016/S0169-4332(02)01353-3

[9] Rajaram, N., Sheik-Ahmad, J. and Cheraghi, S.H. (2003) $\mathrm{CO}_{2}$ Laser Cut Quality of 4130 Steel. International Journal of Machine Tools \& Manufacture, 43, 351-358. https://doi.org/10.1016/S0890-6955(02)00270-5

[10] Sharma, A. and Yadava, V. (2010) Optimization of Kerf Quality Characteristics during Nd:YAG Laser Cutting of Nickel Based Super Alloy Sheet for Straight and Curved Cut Profiles. Optics and Lasers in Engineering, 48, 915-925. https://doi.org/10.1016/j.optlaseng.2010.03.005

[11] Dubey, A. and Yadava, V. (2008) Optimization of Kerf Quality during Pulsed Laser Cutting of Aluminum Alloy Sheet. Journal of Materials Processing Technology, 204, 412-418. https://doi.org/10.1016/j.jmatprotec.2007.11.048

[12] Furukawa, K. (2000) Method for Estimating Service Load from Striation width and Height. Materials Science and Engineering, A285, 80-84. https://doi.org/10.1016/S0921-5093(00)00671-7

[13] Patel, J.M. and Patel, D.M. (2001) Parametric Investigation in $\mathrm{CO}_{2}$ Laser Cutting Quality of Hardox-400 Materials. International Journal of Engineering Science and Technology, 3, 5979-5984.

[14] Abdel Ghany, K. and Newishy, M. (2005) Cutting of 1.2mm Thick Austenitic Stainless Steel Sheet Using Pulsed and CW Nd: YAG Laser. Journal of Materials Processing Technology, 168, 438-447. https://doi.org/10.1016/j.jmatprotec.2005.02.251

[15] Chen, K., Lawrence Yao, Y. and Modi, V. (2001) Gas Dynamic Effects on Laser Cut Quality. Journal of Manufacturing Processes, 3, 38-49. https://doi.org/10.1016/S1526-6125(01)70032-1

[16] Yan, C., Li, L., Li, J., et al. (2005) Review of Surface Quality Study on Laser Sheets Cutting. Laser Technology, 29, 270-274.

[17] Riveiro, A., Quintero, F., Lusquinos, F., Comesaña, R. and Pou, J. (2001) Effects of Processing Parameters on Laser Cutting of Aluminium-Copper Alloys Using OffAxial Supersonic Nozzles. Applied Surface Science, 257, 5393-5397.

https://doi.org/10.1016/j.apsusc.2010.11.061 
[18] Li, X., Zeng, X., Yong, L., et al. (2001) Study of YAG Laser Cutting Process with Stainless Steel Sheet. Chinese Journal of Lasers, A28, 1125-1129.

[19] Yilbas, B. (1993) Anlytical Solution for the Heat Conduction Mechanism Appropriate to the Laser Heating Process. Conduct in Laser Heating Process, 20, 545-555.

[20] Yilbas, B. (1997) Analytical Solution for Time Unsteady Laser Pulse Heating of Semi-Infinite Solid. International Journal of Mechanical Sciences, 39, 671-682. https://doi.org/10.1016/S0020-7403(96)00075-6

[21] Vicaneck, M., Simon, G., Urbassek, H.-M. and Decker, I. (1987) Hydrodynamic Instability of Melt Flow in Laser Cutting. Journal of Physics D: Applied Physics, 20, 140-145. https://doi.org/10.1088/0022-3727/20/1/021

[22] Chen, K., Yao, Y.-L. and Modi, V. (1999) Numerical Simulation of Oxidation Effect in Laser Cutting Process. International Journal of Advanced Manufacturing Technology, 15, 835-842. https://doi.org/10.1007/s001700050140

[23] Powell, J., Al-Mashikhi, S.O., Kaplan, A. and Voisey, K.T. (2001) Fibre Laser Cutting of Thin Section Mild Steel: An Explanation of the "Striation Free" Effect. $O p$ tics and Lasers in Engineering, 49, 1069-1075.

https://doi.org/10.1016/j.optlaseng.2011.03.011

[24] Man, H.C., Duan, T. and Vue, M. (1997) Design and Characteristic Analysis of Supersonic Nozzles for High Gas Pressure Laser Cutting. Journal of Materials Processing Technology, 63, 217-222. https://doi.org/10.1016/S0924-0136(96)02627-1

[25] Lee M. and Lin, L. (2005) An Analytical Model for Striation Formation in Laser Cutting. Applied Surface Science, 247, 277-284. https://doi.org/10.1016/j.apsusc.2005.01.143

[26] Guo, S., Hu, J., Luo, L., et al. (2007) Analysis of Assist Gas Glow and the Structural Optimizing for Simple Supersonic Nozzle in Laser Fusion Cutting. Applied Laser, 27, 403-407.

\section{Submit or recommend next manuscript to SCIRP and we will provide best} service for you:

Accepting pre-submission inquiries through Email, Facebook, LinkedIn, Twitter, etc. A wide selection of journals (inclusive of 9 subjects, more than 200 journals)

Providing 24-hour high-quality service

User-friendly online submission system

Fair and swift peer-review system

Efficient typesetting and proofreading procedure

Display of the result of downloads and visits, as well as the number of cited articles

Maximum dissemination of your research work

Submit your manuscript at: http://papersubmission.scirp.org/

Or contact msa@scirp.org 